\title{
Assessment of Outcome Predictors after First Attack of Optic Neuritis
}

\author{
Mansoureh Mamarabadi, Hadie Razjouyan, Fatemeh Mohammadi, \\ Mehdi Moghaddasi
}

\begin{abstract}
Background: Optic Neuritis (ON) is one of the most common clinically isolated syndromes which develops into clinically diagnosed Multiple Sclerosis (CDMS) over time. Objective: To assess the conversion rate of Iranian patients presenting with idiopathic ON to CDMS as well as monitoring potential demographic and clinical risk factors. Methods: A total of 219 patients' medical records of idiopathic ON from March 2001 to May 2009 were reviewed. Demographic findings, ophthalmologic characteristics on admission and discharge, diagnostic approaches, type and dosage of therapy were retrospectively reviewed. A structured telephone interview was then conducted to identify patients who had subsequently been diagnosed with MS. Survival analysis was used to evaluate the cumulative probability of MS conversion and contributory risk factors. Results: From the 219 ON patients, 109 [age 11-51, female: $81 \%$ ] were followed up. Among the male gender the mean age of patients developing MS was significantly lower ( $\mathrm{P}=0.01)$. In cox regression model, female sex $(\mathrm{p}=0.07)$, bilateral $\mathrm{ON}(\mathrm{p}=0.003)$, MRI abnormalities $(\mathrm{p}<0.001)$ and high dose $(5 \mathrm{~g})$ corticosteroid therapy $(\mathrm{p}<0.001)$ were identified as risk factors for the development of MS. The two and five year cumulative probability of developing MS were $27 \%$ and $45 \%$, respectively. Conclusions: Idiopathic ON in Iranian patients carries higher risk of progression to MS compared to other Asian countries. MRI lesions are the strongest independent risk factor of developing CDMS. Bilateral ON, female gender and high dose corticosteroid therapy are also important factors in predicting CDMS development.
\end{abstract}

RÉSUMÉ: Évaluation des facteurs de prédiction de l'évolution vers la sclérose en plaques suite à un premier épisode de névrite optique. Contexte : La névrite optique (NO) est un des syndromes cliniques isolés les plus fréquents comme précurseur d'une sclérose en plaques diagnostiquée selon les critères cliniques (SPDC). Objectif : Le but de l'étude était d'évaluer le taux de conversion à la SPDC de patients iraniens qui ont consulté pour une NO idiopathique et d'examiner les facteurs de risque démographiques et cliniques potentiels chez ces patients. Méthodes : Deux cent dix-neuf dossiers de patients chez qui un diagnostic de NO idiopathique avait été posé entre mars 2001 et mai 2009 ont été révisés rétrospectivement. Les données démographiques, les caractéristiques ophtalmologiques au moment de l'admission et du congé, les évaluations diagnostiques, le type et le dosage du traitement ont été colligés. Une entrevue téléphonique structurée a ensuite été effectuée pour identifier les patients chez qui un diagnostic de SP avait été posé par la suite. Nous avons utilisé une analyse de survie pour évaluer la probabilité cumulative de conversion à la SP et identifier les facteurs de risque contributifs. Résultats : Cent neuf des 219 patients atteints de NO, dont $81 \%$ étaient des femmes et dont l'âge variait de 11 à 51 ans, ont fait 1'objet d'un suivi. Chez les hommes, l'âge moyen auquel les patients ont présenté une SP était significativement plus bas $(\mathrm{p}=0,01)$. Le modèle de régression de Cox a été utilisé pour identifier les facteurs de risque de présenter une SP, soit le sexe féminin $(p=0,07)$, une NO bilatérale $(p=0,003)$, des anomalies à l'IRM $(\mathrm{p}<0,001)$ et une dose élevée $(5 \mathrm{~g})$ de corticostéroïdes $(\mathrm{p}<0,001)$. La probabilité cumulative de présenter une SP 2 ans et 5 ans après l'épisode de NO était de $27 \%$ et de $45 \%$ respectivement. Conclusions : La NO idiopathique chez les patients iraniens comporte un risque plus élevé de progression à la SP par rapport aux patients d'autres pays asiatiques. Les lésions à l'IRM sont le facteur de risque indépendant le plus important de présenter une SPDC. La NO bilatérale, le sexe féminin et un traitement par corticostéroïdes à haute dose sont également des facteurs de prédiction importants d'une SPDC éventuelle.

Can. J. Neurol. Sci. 2011; 38: 887-895

Multiple Sclerosis (MS) is one of the most common neurologic disorders which cause permanent disability in young adults, especially women ${ }^{1,2}$. The prevalence of the disease in United States was reported as 22-177 per 100,000 with an incidence of 2.7-7.5 per 100,000/year, which is, to some extent, similar to European countries with prevalence and incidence range of 4-200 (per 100,000) and 0.8-8.7 (per 100,000/year). Canada has higher rate of prevalence $(248$ per 100,000$)$. However, the prevalence of the disease in other parts of the world, such as Central and South America, Africa and Asia, seems to be lower ${ }^{3-5}$. The wide range of prevalence of the disease could be attributed to study design and contribution of genetic and environmental factors. Yet, it is a fact that this disease is becoming more widespread, universally ${ }^{3}$. Whether this is a true increase or due to technical and paraclinical progress, or more awareness of physicians, should be determined in well structured systematic reviews.

Multiple sclerosis usually develops sub-clinically ${ }^{2}$ and typically presents with a clinically isolated syndrome $(\mathrm{CIS})^{6}$, e.g.

From Rasool Akram Hospital (MMa, FM, MMo), Tehran University of Medical Sciences, Tehran, Iran; Department of Medicine (HR), Howard University Hospital, Washington, DC, USA

Received April 8, 2011. Final Revisions Submitted June 21, 2011. Correspondence to: Mehdi Moghaddasi, Rasool Akram Hospital, Tehran University of Medical Sciences, Tehran, Iran. 
CIS has been reported in $85 \%$ of people who developed $\mathrm{MS}^{4}$. On the other hand, only $63 \%$ of those who present with CIS will develop MS over 20 years $^{7}$. Optic Neuritis (ON) is one of the most common forms of CIS as well as presenting symptoms of $\mathrm{MS}^{8}$. Consequently, its conversion to MS has been of particular interest to many researchers, who have reported a diverse range of as low as $12 \%$ amongst Mexican patients ${ }^{9}$ to a higher rate of $75 \%$ in Great Britain ${ }^{10}$. The scope of the figures could be explained by a number of factors, including different population with diverse genetic and environmental backgrounds as well as study design, patient selection, length of follow up, change in methods of clinical evaluation and effect of therapy ${ }^{11}$.

Different studies reported several risk factors with various weights on the process of emerging as a full blown MS. Among them, genetic background ${ }^{2,12}$, gender ${ }^{13,14}$, smoking ${ }^{15,16}$, latitude ${ }^{17}$, vitamin D level ${ }^{18,19}$, month of birth ${ }^{20}$, and CIS $^{7}$ are the most emphasized factors. Since $\mathrm{ON}$ is one of the most common manifestations of MS, understanding of the important risk or protective factors can alert physicians of patients who are prone to developing MS over the years. This information could be helpful for making decisions concerning pharmacologic intervention. Several clinical and paraclinical features, such as gender, age, abnormal magnetic resonance imaging (MRI), evoked potentials changes, oligoclonal band changing, and season of $\mathrm{ON}$ attack were found as probable predictors of development of MS after an ON attack a $^{2,8,11,21-24}$. Optic Neuritis Treatment Trial (ONTT) reported that simultaneous MRI abnormalities at $\mathrm{ON}$ attack has strong predictor effect of MS developing; in contrast, optic disc swelling and male sex are against developing MS in future ${ }^{22}$. Although ONTT informed several well established reports, every region should consider their own statistics based on their specific genetics, lifestyle background and environmental exposures. Previously, the prevalence and incidence of MS in Iran was reported as 44 and 3.6 per 100,000 people, which is higher than Asian and African countries but comparable to the Western world ${ }^{3}$. In the present study, we attempted to consider all probable risk factors involved in developing MS and the effects of pharmacologic intervention in a single referral university hospital.

\section{Material \& Methods}

Retrospectively, from March 2001 to January 2009, records of Iranian patients with a first attack of acute ON, referred to the neurology and ophthalmology clinics of Rasool Akram University Hospital, were reviewed. Demographic and clinical information was extracted based on a predefined data sheet. The gathered data included age, sex, telephone number, first admission date, age at the time of ON diagnosis and MS, past medical history, drug history, both eyes evaluation on admission and discharge, recurrence of ON, baseline and follow up MRI, Visual Evoked Potential (VEP), cerebrospinal fluid (CSF) analysis, relative afferent pupillary defect (RAPD), serologic studies for vasculitis disorders, type and dosage of therapies. The Institutional Review Board approved our study be done and all patients reached through phone provided their oral informed consent before proceeding with the questionnaire.

\section{Follow up of patients}

All patients were later contacted by telephone and appointments were arranged to perform physical exams and review their medical records. Where the patient was not accessible, two attempts were made on the same day to contact them, a further two attempts the following days and (to the extent that we were unable to reach him/her), an additional two week trial with the same structure was carried out. If the person was still not accessible, he/she was then considered beyond our reach, although all the information in the chart review was maintained. All the phone calls were made on working days in the afternoon. During the phone call patients were asked about ON recurrence, other symptoms of MS, whether they were diagnosed clinically as having MS and any treatment. The flow chart of patient recruitment is summarized in Figure 1.

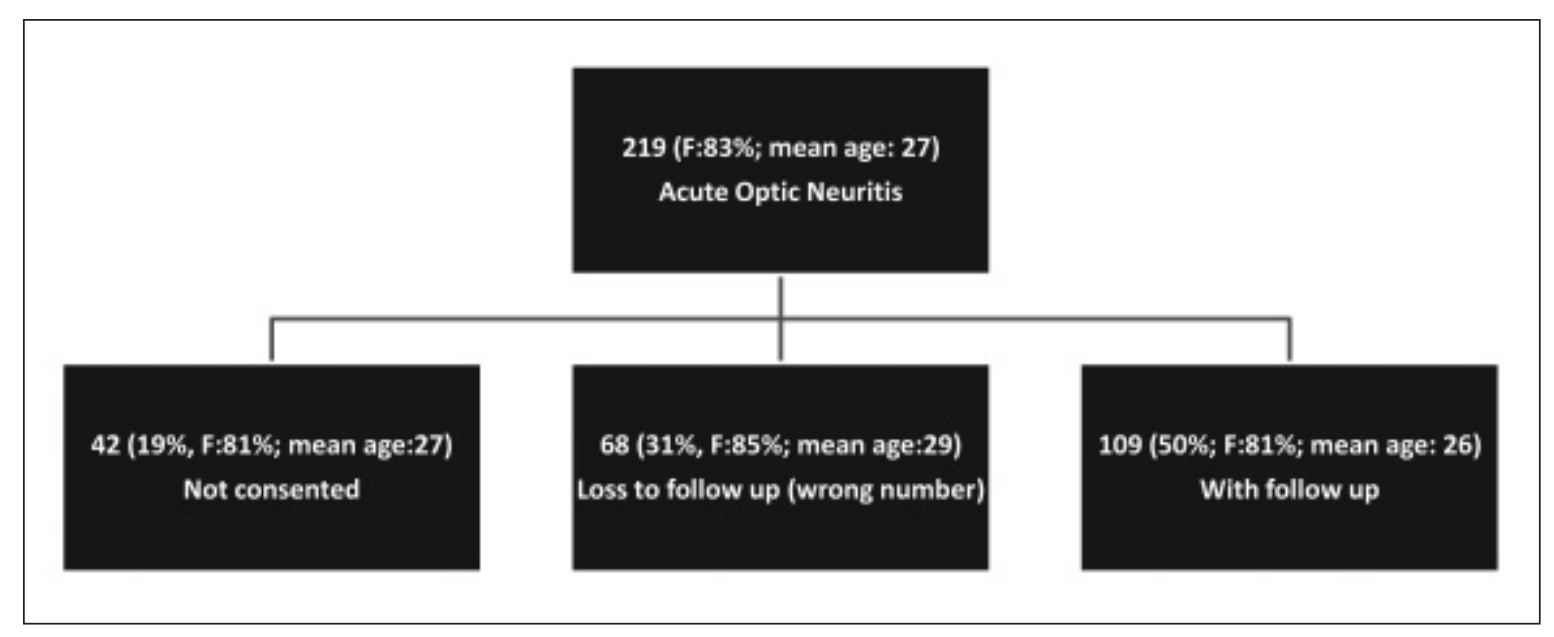

Figure 1: Flow chart of study subjects enrolment. 
Table 1: Demographic characteristics and MRI and therapeutic findings of all patients with first attack of ON as well as those who were followed over years

\begin{tabular}{|c|c|c|c|c|c|}
\hline \multirow[b]{2}{*}{ Variables } & \multirow[b]{2}{*}{$\begin{array}{l}\text { All ON cases } \\
\quad(n=219)\end{array}$} & \multicolumn{4}{|c|}{ Followed cases $(n=109)$} \\
\hline & & $\begin{array}{c}\text { Total } \\
(\mathrm{n}=109)\end{array}$ & $\begin{array}{l}\text { Clinically Diagnosed MS } \\
\qquad(\mathrm{n}=37)\end{array}$ & $\begin{array}{l}\text { Not Diagnosed as } \\
\text { MS }(n=72)\end{array}$ & $P$ value \\
\hline Age, mean (SD) & $27.4(9.1)$ & $26.3(8.3)$ & $26.0(8.1)$ & $26.4(8.5)$ & 0.8 \\
\hline Age Category, No. (\%) & & & & & 0.7 \\
\hline - $\leq 20$ & $55(25.1)$ & $30(27.5)$ & $10(33.3)$ & $20(66.7)$ & \\
\hline - $20-40$ & $140(63.9)$ & $70(64.2)$ & $25(35.7)$ & $45(64.3)$ & \\
\hline - $\quad \geq 40$ & $24(11.0)$ & $9(8.3)$ & $2(22.2)$ & $7(77.8)$ & \\
\hline Gender, No. (\%) & & & & & 0.04 \\
\hline - $\quad$ Male & $37(16.9)$ & $20(18.3)$ & $3(15.0)$ & $17(85.0)$ & \\
\hline - $\quad$ Female & $182(83.1)$ & $89(81.7)$ & $34(38.2)$ & $72(61.8)$ & \\
\hline Season of $1^{\text {st }}$ ON attack, No. (\%) & & & & & 0.5 \\
\hline - $\quad$ Spring & $69(31.5)$ & $32(29.3)$ & $12(37.53)$ & $20(62.5)$ & \\
\hline - $\quad$ Summer & $47(21.5)$ & $21(19.2)$ & $6(28.6)$ & $15(71.40)$ & \\
\hline - $\quad$ Fall & $46(21.0)$ & $23(21.1)$ & $10(43.5)$ & $13(56.5)$ & \\
\hline - $\quad$ Winter & $57(26.0)$ & $33(30.2)$ & $9(27.3)$ & $24(72.7)$ & \\
\hline Baseline MRI finding No. (\%) & & & & & $<0.001$ \\
\hline - Normal & $56(47.0 \%)$ & $36(33.0)$ & $2(5.6)$ & $34(94.4)$ & \\
\hline - $\quad$ Space negative lesion & $34(28.5 \%)$ & $17(15.6)$ & $5(29.4)$ & $12(70.6)$ & \\
\hline - $\quad$ Space positive lesion & $29(24.3 \%)$ & $26(23.9)$ & $20(76.9)$ & $6(23.1)$ & \\
\hline \multicolumn{6}{|l|}{ Corticosteroid Rx } \\
\hline - $\quad$ Dosage & & & & & 0.32 \\
\hline $3 \mathrm{~g}$ & $75(34.2)$ & $30(27.5)$ & $8(26.7)$ & $22(73.3)$ & \\
\hline $5 \mathrm{~g}$ & $144(65.8)$ & $79(72.5)$ & $29(36.7)$ & $50(63.3)$ & \\
\hline - $\quad$ Type of therapy & & & & & 0.39 \\
\hline Intra Venous & $190(86.8)$ & $98(89.9)$ & $32(32.7)$ & $66(67.3)$ & \\
\hline $\begin{array}{l}\text { Intra Venous followed by } \\
\text { oral }\end{array}$ & $29(13.2)$ & $11(10.1)$ & $5(45.5)$ & $6(54.5)$ & \\
\hline
\end{tabular}

\section{Elaboration of variables}

The process of ophthalmic evaluation involved the checking of optic disc edema and looking for papilitis or retrobulbar involvement; visual acuity was determined by Snellen chart and then converted to log MAR to make it more suitable for analysis. A new variable named "affected eye" visual acuity was made based on Log MAR numbers. Those who had both eyes involvement the worse (higher) value was considered for further analysis. To make categorical variables, the log MAR was transformed to mild, moderate and severe categories based on $\log$ MAR VA $\leq 0.3$, between 0.3 and 1.0 and $\geq 1$, respectively. Treatment information such as dosage and route of administration (intravenous or oral) was registered and if the patients received taper therapy after initial dose, this was also recorded. Brain and cervical MRI were used ${ }^{25}$ to look for parenchymal lesions and eventually were categorized as normal, abnormal with space positive lesions and MS like lesions which did not meet space positive criteria ${ }^{26}$. Presence of oligoclonal band and/or IgG index of higher than 0.6 were considered as abnormal CSF analysis.

\section{$O N$ and $M S$ definition}

Recurrent ON was not considered as a factor of CDMS diagnosis. Optic Neuritis that lasted more than 24 hours with seven days progression, accompanied by pain on eye movements, decreased visual acuity, dyschromatopsia and visual field defect, which were not associated with fever and/or other neurological disorders were considered as acute attacks of ON. The diagnosis of clinically definite MS was based on the McDonald and revised McDonald Criteria diagnostic scheme $^{26,27}$.

\section{Statistical analysis}

Numerical data was expressed as mean \pm standard deviation (SD). Student t-test, paired t test and analysis of variance (ANOVA) were used for comparison of means. Non-parametric 
tests were used for numerical data which did not follow normal distribution. Categorical variables were compared using the chisquare test. Survival analysis and cox regression analysis were done to assess rate of developing CDMS and contributing predicting factors. Date of diagnosis of ON was considered as "starting point". Whether the patient were diagnosed as CDMS or not was considered the endpoint of the present study and the attributed date to CDMS diagnosis and last follow up (either the most recent in person evaluation or telephone assessment) for those who did not develop MS was considered the last date of being under the study. Survival curves were made using the Kaplan-Meier method and Life table methods were used to assess the cumulative probability of MS development. Those variables which had a $P$ value less than 0.2 in univariate analysis and/or had biologic plausibility and without more than $20 \%$ missing data were used to develop cox proportional hazards model with a conditional backward method. Hazards ratios are reported with $95 \%$ confidence interval $(\mathrm{CI})$. Reported $\mathrm{P}$ values are all two-tailed and those less than 0.05 were considered statistically significant. Statistical analysis was performed using the SPSS 16.0 software package (IBM Corp., Somers, NY, USA).

\section{RESUlts}

\section{Characteristics of all enrolled patients}

\section{General measures}

Over eight years, 219 patients [mean age (SD): 27.4 (9.1), range: 9-57, female: $83 \%$ ] with the first attack of acute $\mathrm{ON}$ and without any history of being marked as probable or definite MS were selected for this study, (Table 1). A large proportion of our patients $(63.9 \%)$ were aged between 20 and 40 years. All patients underwent corticosteroid therapy with different dosage and route of administration [ $3 \mathrm{~g}$ intravenous (IV) in $65 ; 5 \mathrm{~g}$ IV in $125 ; 3 \mathrm{~g}$ IV followed by oral tapering in $10 ; 5 \mathrm{~g}$ IV followed by oral tapering in 19 cases]. The seasonal distribution of ON attacks is shown in Table 1.

\section{Ophthalmic findings}

Two hundred and seven patients $(94.5 \%)$ had unilateral [right: 99 (47.8\%); left: 108 (52.2\%)] and 12 (5.5\%) suffered from bilateral ON attack. One hundred and fifty-two patients (69.4\%) had retro-bulbar ON with sharp and pink optic disc. The distribution of either right/left or papillitis/retrobulbar eye involvement was not different among age categories of younger than 20, between 20 and 40 and more than 40 years-of-age. $37.8 \%$ of males and $29.1 \%$ of females had papillitis $(p=0.2)$. Among 219 cases, 70 patients had normal visual acuity at discharge time, (Figure 2). Mean visual acuity (SD) of affected eye on admission and discharge were $1.7(0.9)$ and $0.7(0.9)$, respectively $(\mathrm{p}<0.001)$. The values for $3 \mathrm{~g}$ therapy were 1.76 (1.01) and $0.60(0.82)$ [p=0.003]; and $1.79(0.95)$ and $0.80(0.96)$ $[\mathrm{p}<0.001]$ for $5 \mathrm{~g}$ therapy. The mean (SD) decrease of visual acuity $\log$ MAR in $3 \mathrm{~g}$ and $5 \mathrm{~g}$ corticosteroid therapies were 1.15 (1.04), $0.96(0.96)$, respectively $(\mathrm{p}=0.2)$. The mean (SD) decrease of visual acuity log MAR in group with just IV therapy and with mixed IV and oral therapy were $1.06(0.99)$ and 0.76 (0.99), respectively $(\mathrm{p}=0.1)$.

\section{Paraclinical Findings}

Baseline MRI was available for 119 patients $(54.3 \%)$, of whom $56(47.0 \%)$ had normal, 34 (28.5\%) had abnormal but not space positive and $29(24.3 \%)$ had space positive MRI. The Spring was the most common season of ON attacks for those with MRI lesions (41.2\%, $\mathrm{P}=0.09)$. Vasculitis serology profile was checked in 66 patients. Two $(3.0 \%)$ had a positive result and one of them developed to CDMS. Lumbar puncture (LP) was performed in 38 cases and oligoclonal bands were seen in ten

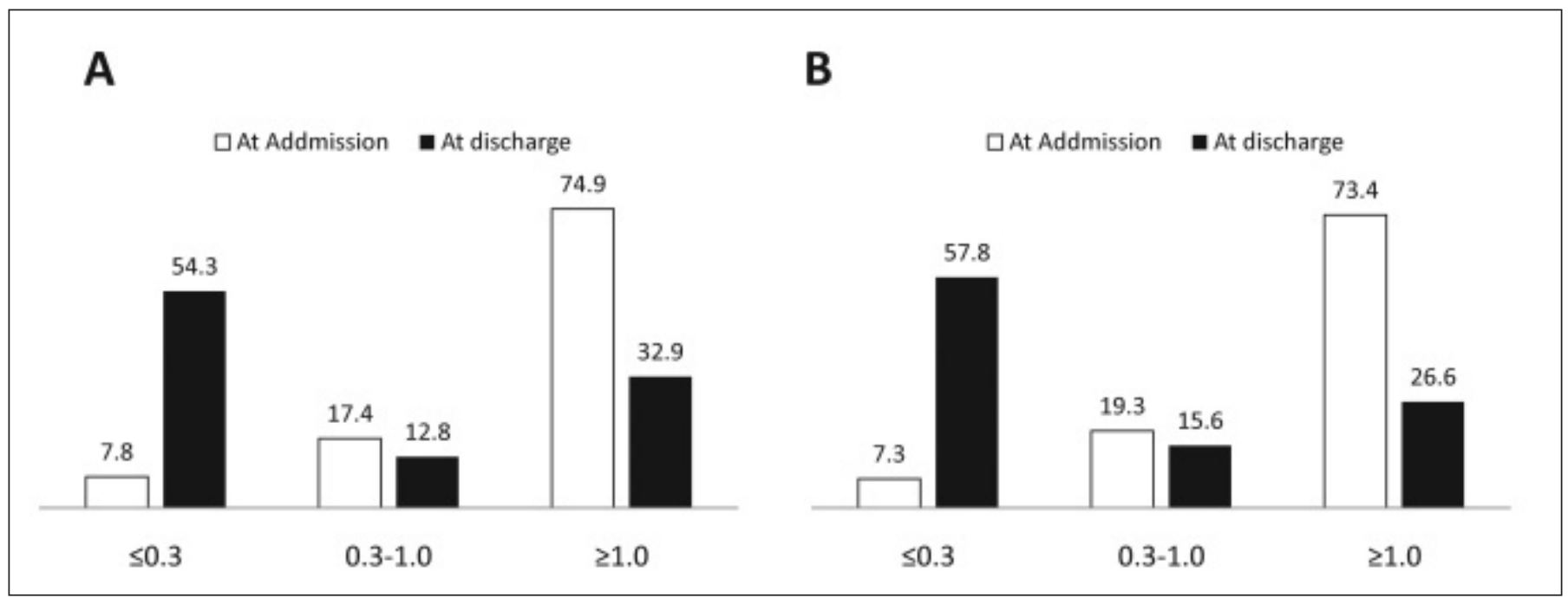

Figure 2: Visual acuity during at time of admission and discharge in all patients $(A, p<0.001)$ and those with follow up $(B, p=0.02)$. 
Table 2: Opthalmologic findings of all patients with first attack of $\mathrm{ON}$ as well as those who were followed over years

\begin{tabular}{|c|c|c|c|c|c|}
\hline \multirow[b]{2}{*}{ Variables } & \multirow[b]{2}{*}{$\begin{array}{c}\text { All ON cases } \\
\quad(n=219)\end{array}$} & \multicolumn{4}{|c|}{ Followed cases $(n=109)$} \\
\hline & & Total $(\mathrm{n}=109)$ & $\begin{array}{c}\text { Clinically Diagnosed } \\
\text { MS ( } \mathrm{n}=37)\end{array}$ & $\begin{array}{l}\text { Not Diagnosed as } \\
\text { MS }(\mathrm{n}=72)\end{array}$ & $\mathrm{P}$ value \\
\hline \multicolumn{6}{|l|}{ Optic Neuritis, No. (\%) } \\
\hline - $\quad$ Uni vs. Bil & & & & & 0.001 \\
\hline Unilateral & $207(94.5)$ & $104(95.4)$ & $32(30.8)$ & $72(69.2)$ & \\
\hline Bilateral & $12(5.5)$ & $5(4.6)$ & $5(100)$ & 0 & \\
\hline - Location & & & & & 0.6 \\
\hline RetroBulbar & $152(69.4 \%)$ & $80(73.4)$ & $28(35.0)$ & $52(65.0)$ & \\
\hline Papillitis & $67(30.6)$ & $29(26.6)$ & $9(31.0)$ & $20(69.0)$ & \\
\hline $\begin{array}{l}\text { Affected eye Visual Acuity on admission, } \\
\text { mean (SD) }\end{array}$ & $1.78(0.97)$ & $1.74(0.97)$ & $1.79(0.97)$ & $1.71(0.98)$ & 0.7 \\
\hline $\begin{array}{l}\text { Affected eye visual acuity on admission, } \\
\text { No. (\%) }\end{array}$ & & & & & 0.3 \\
\hline - $\quad \leq 0.3$ & $17(7.8)$ & $8(7.3)$ & $4(50.0)$ & $4(50.0)$ & \\
\hline - $\quad 0.3-<1$ & $38(17.4)$ & $21(19.3)$ & $5(23.8)$ & $16(76.2)$ & \\
\hline - $\quad \geq 1$ & $164(74.9)$ & $80(73.4)$ & $28(35.0)$ & $52(65.0)$ & \\
\hline $\begin{array}{l}\text { Affected eye Visual Acuity at discharge, } \\
\text { mean (SD) }\end{array}$ & $0.75(0.94)$ & $0.65(0.89)$ & $0.82(0.94)$ & $0.56(0.86)$ & 0.1 \\
\hline $\begin{array}{l}\text { Affected eye visual acuity at discharge, } \\
\text { No. }(\%)\end{array}$ & & & & & 0.3 \\
\hline - $\quad \leq 0.3$ & $119(54.3)$ & $63(57.8)$ & $18(28.6)$ & $45(71.4)$ & \\
\hline - $\quad 0.3-<1$ & $28(12.8)$ & 17 (15.6) & $6(35.3)$ & $11(64.7)$ & \\
\hline - $\quad \geq 1$ & $72(32.9)$ & $29(26.6)$ & $13(44.8)$ & $16(55.2)$ & \\
\hline CSF analysis $(n=38)$ & & & & & 0.007 \\
\hline - $\quad$ Normal & 28 & $18(75)$ & $6(33.3)$ & $12(66.7)$ & \\
\hline - OligoClonal Band & 10 & $6(25)$ & $6(100)$ & 0 & \\
\hline
\end{tabular}

Table 3: The unadjusted and adjusted relative hazard of developing CDMS in patients presenting with first attack of acute optic neuritis using cox regression model

Unadjusted Relative Hazard (95\% CI) P value $\quad$ Adjusted Relative Hazard (95\% $\quad$ P value

\begin{tabular}{|c|c|c|c|c|c|c|}
\hline \multicolumn{7}{|c|}{$\begin{array}{l}\text { Developing CDMS } \\
\text { CDM }\end{array}$} \\
\hline \multicolumn{7}{|c|}{ - Gender } \\
\hline & $\circ$ & Male & 1 & & & \\
\hline & $\circ$ & Female & $2.87(0.88-9.35)$ & 0.08 & $3.82(0.88-16.56)$ & 0.07 \\
\hline • & No. of O & $\mathrm{N}$ attack & $1.21(0.90-1.62)$ & 0.19 & & \\
\hline • & Biateral & vs. unilateral & $7.20(2.74-18.92)$ & $<0.001$ & $6.39(1.90-21.4)$ & 0.003 \\
\hline \multicolumn{7}{|c|}{ - Corticosteroid Rx } \\
\hline & $\circ$ & 3 gram & 1 & & & \\
\hline & $\circ$ & 5 gram & $2.33(1.04-5.20)$ & 0.03 & $14.59(3.59-59.22)$ & $<0.001$ \\
\hline • & Abnorm & al MRI & $4.48(2.46-8.15)$ & $<0.001$ & $6.93(3.43-14.01)$ & $<0.001$ \\
\hline • & Affected & eye VA on admission & $1.10(0.78-1.53)$ & 0.57 & & \\
\hline - & Affected & eye VA at release & $1.30(0.93-1.80)$ & 0.11 & & \\
\hline
\end{tabular}




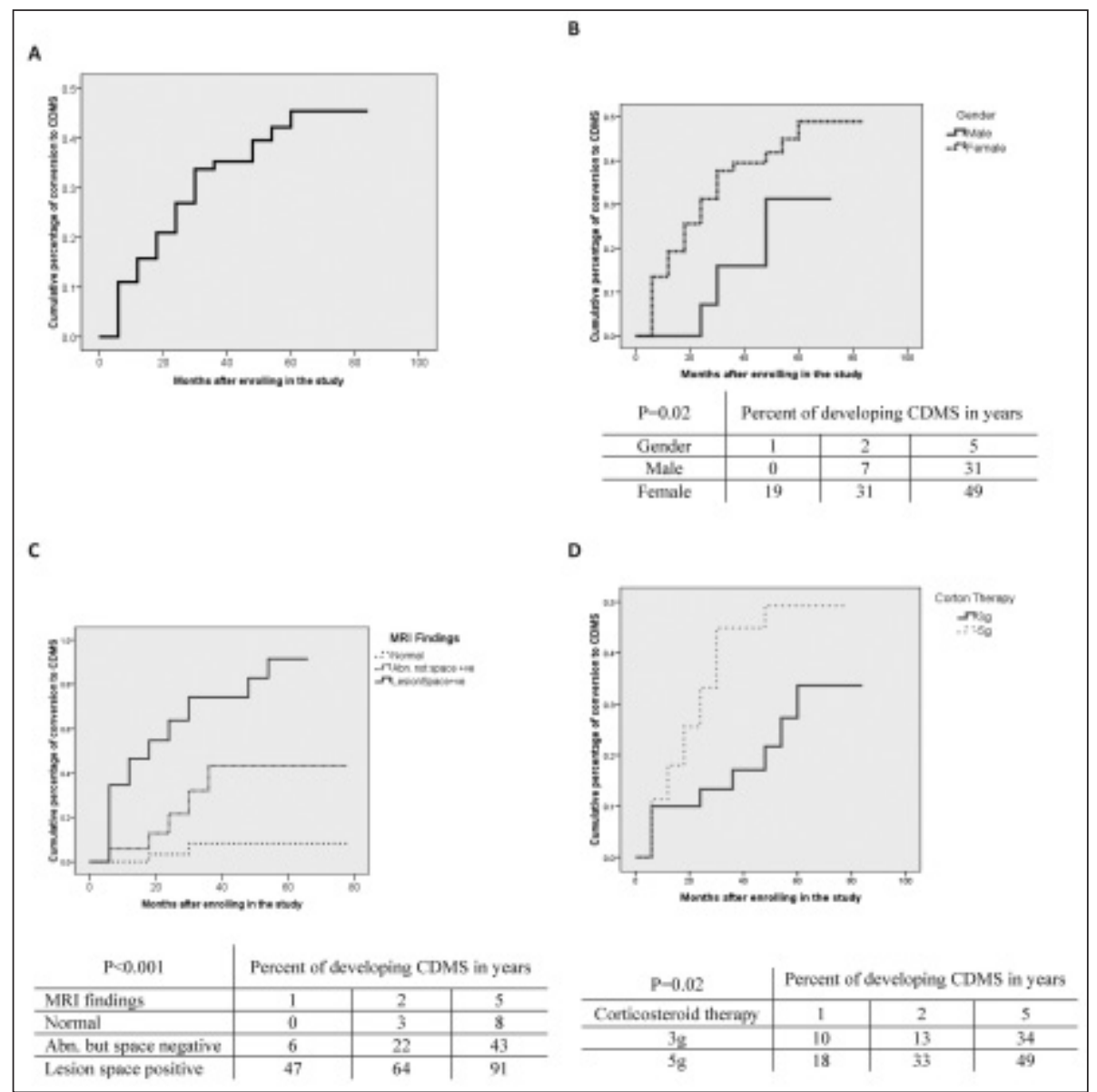

Figure 3: Kaplan-Meier curves showing effect of time (A), gender (B), MRI findings $(C)$ and initial corticosteroid therapy $(D)$ in developing CDMS over time.

(Table 2). VEP was done in 20 followed cases and was abnormal in ten (62.5) and six (37.5) of those with and without diagnosis of MS, respectively $(\mathrm{p}=0.2)$.

\section{Characteristics of all followed patients}

Among all ON patients, 109 [mean age (SD): 26.3 (8.3), range: $11-51$, female: $81 \%$ ] were contacted either by telephone or in person (Figure 1). The mean (SD) months of being under study was 30.5 (22.2) [CDMS: 16.5 (14.8), range: 0-58; nonCDMS: 37.7 (22.1), range: 6-82]. Eye involvement was: right: 43 (39.4\%); left: 61 (56.0\%); bilateral: 5 (4.6\%). 12 (27.9\%) and $20(32.8 \%)$ of those who had right and left eye involvement developed CDMS over time. The basic characteristics of the patients are summarized in Tables 1 and 2. There was a lower rate of CDMS development among patients who were older than 40 years old in comparison to the younger patients. Among the 109 patients with follow up, 40 patients had normal visual acuity at discharge, of which 11 cases developed MS later on.

The mean ages (SD) of men and women were 25.5 (8.4) and $26.4(8.4)$, respectively $(\mathrm{p}=0.6)$. Among the male gender, the mean age (SD) of patients developing MS was significantly less than those who did not develop MS [18.3 (2.8) versus 26.7 (8.5),
$\mathrm{P}=0.01]$. The figures were not different among women $[26.7$ (8.0) vs. 26.3 (8.6), $\mathrm{p}=0.8$ ].

Thirty-one cases had at least another episode of $\mathrm{ON}$ with mean interval time (SD) of 12.1 (1.3) months. Three of these patients had bilateral eye involvement on first admission. Among those with the second unilateral eye involvement, the lateralization was statistically different between the two attacks, i.e. those who had right eye involvement at admission (11), developed left eye $\mathrm{ON}$ at the recurrence $(8,72.7 \%)$ or those who had left eye involvement at admission (17), developed right eye $(12,70.6 \%)$ involvement at the second attack $(\mathrm{P}=0.05)$. Among those who had more than one ON attack $(n=31), 19$ were followed up and 5 of them (26.3\%) developed CDMS. A further two patients suffered three attacks of $\mathrm{ON}$ and both went on to developed MS.

After one year of follow-up, $16 \%$ of the cases progressed to CDMS. The values after two and five years were $27 \%$ and $45 \%$, respectively (Figure 3). The longtime effect of gender, MRI findings, and corticosteroid therapy on developing CDMS is depicted in Figure 3. Gender, number of ON attacks, lateralization of eye involvement, corticosteroid therapy, abnormal MRI findings, VA of affected eye on admission and 
discharge were used for univariate and multivariate analysis (Table 3). In univariate analysis, female gender (RH: 2.87, 95\% CI: 0.88-9.35), bilateral eye involvement (RH: $7.20,95 \% \mathrm{CI}$ : 2.74-18.92), high dose corticosteroid therapy (RH: $2.33,95 \%$ CI: 1.04-5.20), and abnormal MRI findings (RH: 4.48, 95\% CI: 2.46-8.15) were associated with an increase in the relative hazard of developing CDMS. Using multivariate analysis, abnormal MRI findings, bilateral eye involvement and high dose corticosteroid therapy were independently associated with increased risk of developing CDMS (Table 3).

\section{Discussion}

A clinically isolated syndrome (CIS) is an attack compatible with MS, and ON is one of the most common forms of CIS. An episode of CIS can create a diagnostic and therapeutic dilemma. $63 \%$ of those who present with CIS will progress to MS over a period of 20 years $^{7}$. Some evidences suggest that early treatments may improve the eventual outcome ${ }^{28}$. Our study showed that the risk of developing CDMS two and five years after an initial ON attack in Iranian patients would be $27 \%$ and $45 \%$, respectively. Stratifying based on gender, showed that younger men stand a higher risk of developing CDMS. Gender, MRI lesions, oligoclonal band in CSF, bilateral eye involvement and high dose corticosteroid therapy play a role in defining the risk of developing CDMS. However, only MRI lesions, bilateral eye involvement and high dose corticosteroid therapy were independently associated with an increased risk of developing CDMS. Although corticosteroid therapy was very helpful in prompt visual recovery, the high dosage may nonetheless eventually contribute to unwanted clinical development of CDMS.

The rate of CDMS development after an attack of ON was relatively high in our study in comparison to other Asian countries $^{21,23}$ and is comparable to Western ones ${ }^{11,22,29}$, see Table 4. This disparity could be explained by genetic backgrounds such as common origin of European countries and Iranians from Arian descent while other mentioned Asian countries consist of different ethnicities. Our values are higher than those previously reported from Iran $^{30}$ which mostly could be explained by the use of different MS definitions (Poser vs. McDonald), sample size (56 vs. 109), method of analysis and length of follow up. However, it could be due to a change in conversion rate of $\mathrm{ON}$ into CDMS which can be explained by the high prevalence and incidence of MS in $\operatorname{Iran}^{3}$. Our results showed that the female sex carries a higher risk of developing CDMS in the future but in multivariate cox regression analysis its effect is to some extent masked by the presence of lesions in MRI findings which is consistent with $\mathrm{ONTT}^{22}$. Once we tried to check for factors involved in developing CDMS by gender, sign of ON attack at a young age was an important predictor of CDMS development in

Table 4: Rate of CDMS development in different studies over the last three decades

\begin{tabular}{|c|c|c|c|c|c|c|}
\hline Author & Country & Latitude & Year & $\begin{array}{c}\text { No. of enrolled } \\
\text { patients }\end{array}$ & $\begin{array}{l}\text { Percent of patients } \\
\text { developed MS }\end{array}$ & $\begin{array}{c}\text { Mean follow } \\
\text { up (yrs) }\end{array}$ \\
\hline Isayama et al [34] & Japan & $24.02 \mathrm{~N}-45.31 \mathrm{~N}$ & 1982 & 84 & 8.3 & 5.2 \\
\hline Hely et al[35] & Australia & $43.38 \mathrm{~S}-09.13 \mathrm{~S}$ & 1986 & 82 & 42 & 7 \\
\hline \multirow[t]{3}{*}{ Francis et al[10] } & UK & $49.57 \mathrm{~N}-55.48 \mathrm{~N}$ & 1987 & 101 & 40 & 3.9 \\
\hline & & & & & 57 & 11.6 \\
\hline & & & & & 75 & 15 \\
\hline Rizzo et al[36] & USA & $24.31 \mathrm{~N}-49.00 \mathrm{~N}$ & 1988 & 60 & Men: 34\%; women: $74 \%$ & 14.9 \\
\hline Sandberg-wollheim et al[37] & Sweden & $55.20 \mathrm{~N}-69.03 \mathrm{~N}$ & 1990 & 86 & 45 & 15 \\
\hline Corona-Vazquez et al.[9] & Mexico & $14.32 \mathrm{~N}-32.42 \mathrm{~N}$ & 1994 & 110 & 12 & 7 \\
\hline Rodriguez et al[38] & USA & $24.31 \mathrm{~N}-49.00 \mathrm{~N}$ & 1995 & 95 & 39 & 10 \\
\hline Soderstrom et al[37] & Sweden & $55.20 \mathrm{~N}-69.03 \mathrm{~N}$ & 1998 & 147 & 36 & 2.1 \\
\hline O’Riordan et al[29] & UK & $49.57 \mathrm{~N}-55.48 \mathrm{~N}$ & 1998 & 81 & 59 & 10 \\
\hline \multirow[t]{2}{*}{ Ghezzi et al[11] } & Italy & $36.38 \mathrm{~N}-47.03 \mathrm{~N}$ & 1999 & 102 & 13 & 2 \\
\hline & & & & & 42 & 8 and 10 \\
\hline AmirZargar et al[30] & Iran & $25.03 \mathrm{~N}-39.46 \mathrm{~N}$ & 2005 & 56 & 26.7 & 4 \\
\hline Lin et al[21] & Taiwan & $21.53 \mathrm{~N}-25.17 \mathrm{~N}$ & 2006 & 109 & 14.3 & 5 \\
\hline ONTT[22] & Europe & & 2008 & 389 & 50 & 15 \\
\hline Kazim et al[23] & Pakistan & $23.00 \mathrm{~N}-37.00 \mathrm{~N}$ & 2010 & 253 & 14.6 & 5 \\
\hline Present Study & Iran & $25.03 \mathrm{~N}-39.46 \mathrm{~N}$ & 2011 & 119 & 45.0 & 5 \\
\hline
\end{tabular}


the male sex. Spring and Winter were the most frequent seasons during which ON attacks occurred. In conducting our research for MRI lesions, we found that Spring was the most common season for ON in patients with abnormal MRI findings.

The ON was mostly retrobulbar which is consistent with Western countries ${ }^{8,22}$ but not Eastern ones ${ }^{21,23}$. Although the CDMS development was higher among retrobulbar cases (35\% vs. $31 \%$ non-retrobulbar cases), it was not statistically significant. Our results showed that bilateral ON is an important risk factor in the development of CDMS and can increase the probability of developing CDMS six-fold. This is consistent with the Hutchinson report which studied 136 cases with ON and found that the rate of developing MS was higher in patients with bilateral ON than those with unilateral ON (65\% vs. $44 \%$ respectively $)^{31}$. Other studies have not selected bilateral $\mathrm{ON}$ in their studies which makes comparison impossible. The VA on admission was not associated with CDMS development. However, VA at discharge could be a potential risk factors for developing CDMS in the future but it needs to be confirmed with more patients.

We could not find any association between abnormal VEP and development of CDMS; however, those who had oligoclonal band in CSF developed CDMS over time which is consistent with previous studies ${ }^{8,21,32}$. There is a strong link between normal MRI and lower rate of the development of CDMS (Figure 3 and Table 3) which confirms the ONTT results as well as others ${ }^{8,22,23}$. On the other hand, abnormal findings on MRI should be approached seriously with proper treatment as well as short interval follow ups.

Corticosteroids have been used as one of the most common forms of therapy in acute ON. It also had promising results in relieving the visual difficulties of our patients. Our results illustrated that both 3 and 5 gram therapies improved visual acuity of the patients during their acute phase of attack. This is consistent with the results of the ONTT and Sellebjerg et al studies. ${ }^{28}$ Moreover, we found that the 3 gram therapy method appeared to generate better initial outcome. The ONTT study illustrated that 3 grams IV corticosteroid therapy followed by a two weeks taper will accelerate visual recovery, however, Vedula et al were not able to describe effectiveness of corticosteroid therapy ${ }^{33}$. In their systematic review they were not able to conclude on the effectiveness of corticosteroid therapy on visual acuity improvement. It seems that their report should be interpreted cautiously as they were not able to conduct further analysis due to heterogeneity of data.

According to our data, those who managed with a higher dose $(5 \mathrm{~g})$ of corticosteroid therapy, had more chance of developing CDMS than those treated with a lower dose (3g), [Figure 3]. Some may claim that those who got higher dose had worse VA on admission but the distribution of corticosteroid dosage and severity of VA impairment was not statistically significant which would reject this hypothesis. Furthermore, the treatment strategy was not based on severity of visual acuity or MRI findings; it was just a physician preference. Since the therapy selection was not randomized and blind, the result of this part should be interpreted cautiously. The explanation of different eventual outcome of $3 \mathrm{~g}$ and $5 \mathrm{~g}$ corticosteroid therapies may remain in the fact of overwhelming immunity suppression with high dose therapy. However, this will need to be elucidated by prospective double blind clinical trials.
The strength of the present study is the use of the survival method of analysis since standard methods of analysis such as logistic regression and mean time to reach the end point can give misleading results due to censored data. In addition, this study benefited from using the McDonald criteria to diagnose MS at a single center. In contrast, the limitations of this research are the inherent retrospective nature of the study, limited long-term follow up of the original cohort of 219 patients (109 patients).

In conclusion, $45 \%$ of Iranian patients referring to our center with first acute attack of ON developed CDMS after five years. The MRI lesions were the strongest independent risk factor of developing CDMS. Bilateral ON, female gender, and CSF abnormalities were also important factors in predicting CDMS development. In addition, younger age in males was more likely to lead to development of CDMS. The inadvertent effect of high dose corticosteroid therapy needs to be investigated with double controlled randomized clinical trials.

\section{REFERENCES}

1. Noseworthy JH, Lucchinetti C, Rodriguez M, Weinshenker BG. Multiple sclerosis. N Engl J Med. 2000; 343(13):938-52.

2. Ramagopalan SV, Dobson R, Meier UC, Giovannoni G. Multiple sclerosis: risk factors, prodromes, and potential causal pathways. Lancet Neurol. 2010; 9(7):727-39.

3. Milo R, Kahana E. Multiple sclerosis: geoepidemiology, genetics and the environment. Autoimmun Rev. 2010; 9(5):A387-94.

4. Poppe AY, Wolfson C, Zhu B. Prevalence of multiple sclerosis in Canada: a systematic review. Can J Neurol Sci. 2008; 35(5): 593-601.

5. Beck CA, Metz LM, Svenson LW, Pattern SB. Regional variation of multiple sclerosis prevalence in canada. Mult Scler. 2005; 11 (5):516-9.

6. Miller D, Barkhof F, Montalban X, Thompson A, Filippi M. Clinically isolated syndromes suggestive of multiple sclerosis, part I: natural history, pathogenesis, diagnosis, and prognosis. Lancet Neurol. 2005; 4(5):281-8.

7. Fisniku LK, Brex PA, Altmann DR, et al. Disability and T2 MRI lesions: a 20-year follow-up of patients with relapse onset of multiple sclerosis. Brain. 2008; 131(Pt 3):808-17.

8. Nilsson P, Larsson EM, Maly-Sundgren P, Perfekt R, SandbergWolheim M. Predicting the outcome of optic neuritis: evaluation of risk factors after 30 years of follow-up. J Neurol. 2005; 252(4):396-402.

9. Corona-Vazquez T, Ruiz-Sandoval J, Arriada-Mendicoa N. Optic neuritis progressing to multiple sclerosis. Acta Neurol Scand. 1997; 95(2):85-9.

10. Francis DA, Compston DA, Batchelor JR, McDonald WI. A reassessment of the risk of multiple sclerosis developing in patients with optic neuritis after extended follow-up. J Neurol Neurosurg Psychiatry. 1987; 50(6):758-65.

11. Ghezzi A, Martinelli V, Torri V, et al. Long-term follow-up of isolated optic neuritis: the risk of developing multiple sclerosis, its outcome, and the prognostic role of paraclinical tests. J Neurol. 1999; 246(9):770-5.

12. Ebers GC, Sadovnick AD, Dyment DA, Yee IM, Willer CJ, Risch N. Parent-of-origin effect in multiple sclerosis: observations in half-siblings. Lancet. 2004; 363(9423):1773-4.

13. Hirst C, Ingram G, Pickersgill T, Swingler R, Compston DA, Robertson NP. Increasing prevalence and incidence of multiple sclerosis in South East Wales. J Neurol Neurosurg Psychiatry. 2009; 80(4):386-91.

14. Alonso A, Hernan MA. Temporal trends in the incidence of multiple sclerosis: a systematic review. Neurology. 2008; 71(2):129-35.

15. Hedstrom AK, Baarnhielm M, Olsson T, Alfredsson L. Tobacco smoking, but not Swedish snuff use, increases the risk of multiple sclerosis. Neurology. 2009; 73(9):696-701. 
16. Hawkes $\mathrm{CH}$. Smoking is a risk factor for multiple sclerosis: a metanalysis. Mult Scler. 2007; 13(5):610-5.

17. Kurtzke JF. Geographic distribution of multiple sclerosis: An update with special reference to Europe and the Mediterranean region. Acta Neurol Scand. 1980; 62(2):65-80.

18. Kampman MT, Brustad M. Vitamin D: a candidate for the environmental effect in multiple sclerosis - observations from Norway. Neuroepidemiology. 2008; 30(3):140-6.

19. Munger KL, Zhang SM, O'Reilly E, et al. Vitamin D intake and incidence of multiple sclerosis. Neurology. 2004; 62(1):60-5.

20. Willer CJ, Dyment DA, Sadovnick AD, et al. Timing of birth and risk of multiple sclerosis: population based study. BMJ. 2005; 330(7483):120.

21. Lin YC, Yen MY, Hsu WM, Lee HC, Wang AG. Low conversion rate to multiple sclerosis in idiopathic optic neuritis patients in Taiwan. Jpn J Ophthalmol. 2006; 50(2):170-5.

22. Optic Neuritis Study Group. Multiple sclerosis risk after optic neuritis: final optic neuritis treatment trial follow-up. Arch Neurol. 2008; 65(6):727-32.

23. Kazim SF, Islam M, Khan M, Hameed B, Shafqat S. Risk of multiple sclerosis after idiopathic optic neuritis in a Pakistani population. Can J Neurol Sci. 2010; 37(2):258-63.

24. Balashov KE, Pal G, Rosenberg ML. Optic neuritis incidence is increased in spring months in patients with asymptomatic demyelinating lesions. Mult Scler. 2010; 16(2):252-4.

25. Beck RW, Arrington J, Murtagh FR, Cleary PA, Kaufman DI. Brain magnetic resonance imaging in acute optic neuritis. Experience of the Optic Neuritis Study Group. Arch Neurol. 1993; 50(8): 841-6.

26. McDonald WI, Compston A, Edan G, et al. Recommended diagnostic criteria for multiple sclerosis: guidelines from the International Panel on the diagnosis of multiple sclerosis. Ann Neurol. 2001; 50(1): 121-7.

27. Polman $\mathrm{CH}$, Reingold SC, Edan G, et al. Diagnostic criteria for multiple sclerosis: 2005 revisions to the "McDonald Criteria". Ann Neurol. 2005; 58(6):840-6.
28. Sellebjerg F, Nielsen HS, Frederiksen JL, Olesen J. A randomized, controlled trial of oral high-dose methylprednisolone in acute optic neuritis. Neurology. 1999; 52(7):1479-84

29. O'Riordan JI, Thompson AJ, Kingsley DP, et al. The prognostic value of brain MRI in clinically isolated syndromes of the CNS. A 10-year follow-up. Brain. 1998; 121 (Pt 3):495-503.

30. Amirzargar AA, Tabasi A, Khosravi F, et al. Optic neuritis, multiple sclerosis and human leukocyte antigen: results of a 4-year follow-up study. Eur J Neurol. 2005; 12(1):25-30.

31. Hutchinson WM. Acute optic neuritis and the prognosis for multiple sclerosis. J Neurol Neurosurg Psychiatry. 1976; 39(3): 283-9.

32. Jacobs LD, Kaba SE, Miller CM, Priore RL, Brownscheidle CM. Correlation of clinical, magnetic resonance imaging, and cerebrospinal fluid findings in optic neuritis. Ann Neurol. 1997; 41(3):392-8.

33. Vedula SS, Brodney-Folse S, Gal RL, Beck R. Corticosteroids for treating optic neuritis. Cochrane Database Syst Rev. 2007; 24(1): CD001430

34. Isayama Y, Takahashi T, Shimoyoma T, Yamadori A. Acute optic neuritis and multiple sclerosis. Neurology. 1982; 32(1):73-6.

35. Hely MA, McManis PG, Doran TJ, Walsh JC, Mcleod JG. Acute optic neuritis: a prospective study of risk factors for multiple sclerosis. J Neurol Neurosurg Psychiatry. 1986; 49(10):1125-30.

36. Rizzo JF, 3rd, Lessell S. Risk of developing multiple sclerosis after uncomplicated optic neuritis: a long-term prospective study. Neurology. 1988; 38(2):185-90.

37. Soderstrom M. Optic neuritis and multiple sclerosis. Acta Ophthalmol Scand. 2001; 79(3):223-7.

38. Rodriguez M, Siva A, Cross SA, O'Brien PC, Kurland LT. Optic neuritis: a population-based study in Olmsted County, Minnesota. Neurology. 1995; 45(2):244-50. 